\title{
Enhanced sulfate reduction with acidogenic sulfate-reducing bacteria
}

\author{
Aijie Wang ${ }^{\text {a }}$, Nanqi Ren ${ }^{\mathrm{a}}$, \\ Xu Wang ${ }^{\mathrm{a}}$, Duujong Lee ${ }^{\mathrm{a}, \mathrm{b}, *}$ \\ ${ }^{a}$ School of Municipal \& Environmental Engineering, Harbin Institute of Technology, \\ P.O. Box 2614, 202 Haihe Road, Harbin 150090, China \\ ${ }^{\mathrm{b}}$ Department of Chemical Engineering, National Taiwan University, Taipei 10617, Taiwan \\ Received 3 May 2007; received in revised form 10 October 2007; accepted 6 November 2007 \\ Available online 17 November 2007
}

\begin{abstract}
Sulfate reduction in a continuous flow, acidogenic reactor using molasses wastewater as the carbon source was studied at varying chemical oxygen demand/sulfate $\left(\mathrm{COD} / \mathrm{SO}_{4}{ }^{2-}\right)$ ratios. At a critical COD/SO${ }_{4}{ }^{2-}$ ratio of 2.7 , neither COD nor sulfate were in excess for extra production of ethanol or acetate in the reactor. An acetic-type microbial metabolism was established with sulfate-reducing bacteria (SRB) significantly consuming hydrogen and volatile fatty acids produced by acidogenic bacteria and hydrogen producing acetogens in degrading COD, thereby yielding sulfate removal rate $>94.6 \%$. A low critical COD/ $\mathrm{SO}_{4}{ }^{2-}$ ratio of 1.6 was also observed with the enriched ASRB population in reactor which overcomes the barrier to the treatment capability of sulfate-laden wastewater treatment with limited COD supply.
\end{abstract}

(C) 2007 Elsevier B.V. All rights reserved.

Keywords: Sulfate-reducing; $\mathrm{COD} / \mathrm{SO}_{4}{ }^{2-}$ ratio; Acetate; Metabolism

\section{Introduction}

The sulfate-reducing bacteria (SRB) present a unique microbial group responsible for the noted sulfate reduction capability with organic matters or hydrogen as electron donors. The SRB can suppress methane-producing bacteria (MPB) through competition for the same substrates such as hydrogen and acetate, and consequently result in a primary inhibition to MPB [1,2]. Moreover, the SRB can convert sulfate into sulfide which can poison MPB and decrease methane production [3-5]. The chemical oxygen demand (COD)/ $/ \mathrm{SO}_{4}{ }^{2-}$ ratio in influent significantly affected the metabolic pathways of SRB [6,7].

Five main microbial groups co-exist in the acidogenic sulfatereducing reactor: acidogenic bacteria $(\mathrm{AB})$, hydrogen producing acetogens (HPA), hydrogen-utilizing SRB (HSRB), acetic acidutilizing SRB (ASRB), and fatty acid-utilizing SRB (FSRB). The FSRB includes propionic acid-utilizing SRB (p-SRB),

\footnotetext{
* Corresponding author at: Department of Chemical Engineering, National Taiwan University, Taipei 10617, Taiwan. Tel.: +886 23625632; fax: +886223623040 .

E-mail address: djlee@ntu.edu.tw (D. Lee).
}

butyric acid-utilizing SRB (b-SRB), and lactic acid-utilizing SRB (1-SRB). The SRB manipulate hydrogen transfer in the overall anaerobic metabolic processes [8]. Furthermore, the SRB compete better than the HPA for the same substrate, such as propionate, butyrate, and benzophenone [9]. The knowledge on how different co-existing microbial groups interact in such a complicated ecosystem is limited.

Wang [10] noted that the metabolites of sulfate-reducing reaction are mainly composed of acetate, indicating that the metabolic pathway resembles an "acetic acid-type microbial metabolism". Wang et al. [11] indicated that the electron-flow to $\mathrm{SRB}$ decreases with increasing $\mathrm{COD} / \mathrm{SO}_{4}{ }^{2-}$ ratio. These authors claimed that the SRB populations consumed hydrogen to a low level for achieving high sulfate removal efficiency of sulfate in the reactor.

This work aims at exploring the metabolic pathways of SRB in an acidogenic sulfate-reducing bioreactor and demonstrating how the acetic acid-type microbial metabolism was possibly formed in response to complicated interactions between different microbial populations. The accumulation of acetate as end product limits the sulfate treatment efficiency in the reactor. Therefore, this study enriched ASRB in the reactor to achieve 
Table 1

Operational conditions of continuous tests

\begin{tabular}{|c|c|c|c|c|c|}
\hline \multirow[t]{2}{*}{ Experiment phase } & \multicolumn{5}{|c|}{ Operational conditions } \\
\hline & $\mathrm{COD} / \mathrm{SO}_{4}{ }^{2-}$ ratio & $\mathrm{COD}\left(\mathrm{mg} \mathrm{l}^{-1}\right)$ & $\mathrm{SO}_{4}^{2-}\left(\mathrm{mg} \mathrm{l}^{-1}\right)$ & $N s\left(\mathrm{~kg} \mathrm{SO}_{4}{ }^{2-} \mathrm{m}^{-3} \mathrm{~d}^{-1}\right)$ & HRT (h) \\
\hline Phase a & 4.5 & 3220 & 715 & 1.4 & 10.6 \\
\hline Phase $\mathrm{b}$ & 3.6 & 3220 & 894 & 1.9 & 10.6 \\
\hline Phase c & 2.7 & 3220 & 1190 & 2.5 & 10.6 \\
\hline Phase d & 1.9 & 3220 & 1490 & 3.6 & 10.6 \\
\hline Phase e & 0.9 & 3220 & 3580 & 7.5 & 10.6 \\
\hline
\end{tabular}

complete oxidation of COD to effectively reduce sulfate at a low $\mathrm{COD} / \mathrm{SO}_{4}{ }^{2-}$ ratio.

\section{Materials and methods}

\subsection{Substrates and continuous tests}

The acidogenic sulfate-reducing reactor, a continuous stirred tank reactor (CSTR) with an internal gas-liquid-solid threephase separator used in Wang et al. [11], was the testing reactor. The reactor had an effective volume of 9.71 . Sodium sulfate was the electron acceptor and molasses wastewater from a beet sugar refinery was the electron donor. Diammonium phosphate supplemented nitrogen and phosphate sources in molasses wastewater.

The waste activated sludge collected at the secondary clarifier in the wastewater treatment plant a petroleum refining plant was incubated in the molasses wastewater dosed with sodium sulfate without mixing for 1 month. This inoculum was seeded in the reactor at volatile suspended solids of $11.7 \mathrm{~g}^{-1}$. Since the generation time for SRB is generally larger than the HRT applied in this study (10.4 h) [12], hence, $1200 \mathrm{~g}$ of activated carbon (size $0.3-0.5 \mathrm{~mm}$, specific gravity of $1.41 \mathrm{~g} \mathrm{~cm}^{-3}$ ) was added to the reactor for biofilm development. On day 151 the alkalinity of influent was adjusted at $700 \mathrm{mg} \mathrm{l}^{-1}$ by supplying $\mathrm{NaHCO}_{3}$. The reactor was design to be able to keep an anaerobic atmosphere but still with easy $\mathrm{H}_{2} \mathrm{~S}$ gas release. Temperatures was kept at $35 \pm 1{ }^{\circ} \mathrm{C}$ in all tests. Nitrogen gas purged the bottles before the tests.

The reactor was started up with influent of $\mathrm{COD} / \mathrm{SO}_{4}{ }^{2-}=5 / 1$, $\mathrm{SO}_{4}{ }^{2-}=660 \mathrm{mgl}^{-1}$, and sulfate loading rate $(\mathrm{Ns})=1.4 \mathrm{~kg}$ $\mathrm{SO}_{4}{ }^{2-} \mathrm{m}^{-3} \mathrm{~d}^{-1}$. The hydraulic retention time (HRT) of the wastewater was set at $23.3 \mathrm{~h}$ during day $1-10$, then the HRT was decreased to $10.6 \mathrm{~h}$ since day 11 and onward. After 30 days of start-up, the sulfate removal ratio reached up to $98 \%, \mathrm{pH}$ dropped from 6.6 to 5.4-5.7, alkalinity increased from around 140 to $650-800 \mathrm{mg}^{-1}$, and the oxidation reduction potentials
(ORP) dropped from -200 to $-320 \mathrm{mV}, \mathrm{S}^{2-}$ concentration increased from 0 to $64 \mathrm{mgl}^{-1}$, and total volatile fatty acids (VFA) increased from around 100 to $1500 \mathrm{mg} \mathrm{l}^{-1}$. The reactor was considered successfully started up when its performance was stable over 2 weeks.

After successful start-up of the reactor, the influent was adjusted according to the five phases indicated in Table 1. Restated, the reactor was operated sequentially at $\mathrm{COD} / \mathrm{SO}_{4}{ }^{2-}$ ratio of 4.5, 3.6, 2.7, 1.9, and 0.9, with fixed COD $\left(3220 \mathrm{mg}^{-1}\right)$ and HRT indicated. The operation was performed until the reactor had reached a steady-state, regarding the sulfate removal rate and the distributions of end products.

\subsection{Enrichment test of ASRB}

The waste activated sludge collected for the above continuous tests was incubated in a still suspension with added acetate and sulfate for 1 month. Then a CSTR of effective volume 1.01 was seeded with the incubated sludge (VSS of $8.7 \mathrm{gl}^{-1}$ ) and was fed with an influent containing of acetate as sole carbon source (in COD of $1000 \mathrm{mg} \mathrm{l}^{-1}$ ) and sulfate $\left(500 \mathrm{mg} \mathrm{l}^{-1}\right.$ ) at an HRT of $9.6 \mathrm{~h}$. Diammonium phosphate supplemented nitrogen and phosphate sources in molasses wastewater. Temperatures was kept at $35 \pm 1{ }^{\circ} \mathrm{C}$.

The sulfate removal ratio noted for the enriched bacteria using acetate as the sole carbon source increased with time, and reached over $80 \%$ after 20 days of enrichment (data not shown). Hence, the ASRB was enriched and activated in the bioreactor. Other SRB populations should be significantly inhibited owing to substrate limitation.

\subsection{Substrates and batch tests}

Parallel batch fermentation tests were conducted in $100 \mathrm{ml}$ culture bottles, three parallel bottles under each experimental

Table 2

Comparison of metabolites from batch test A

\begin{tabular}{|c|c|c|c|c|c|c|c|c|c|}
\hline \multirow[t]{2}{*}{ Batch Test } & \multicolumn{6}{|c|}{ End products (mg COD $\left.{ }^{-1}\right)$} & \multirow[t]{2}{*}{ Acetate/EtOH } & \multirow[t]{2}{*}{$\mathrm{EtOH} / \mathrm{EtOH}+\mathrm{VFA}(\%)$} & \multirow[t]{2}{*}{ Acetate/EtOH + VFA (\%) } \\
\hline & $\mathrm{EtOH}$ & Acetate & Propionate & Butyrate & Valerate & $\mathrm{EtOH}+\mathrm{VFA}$ & & & \\
\hline Test A-1 & 601 & 637 & 172 & 224 & 54.1 & 1690 & 1.1 & 35.6 & 37.7 \\
\hline Test A-2 & 283 & 1040 & 224 & 182 & 28.1 & 1750 & 3.7 & 16.1 & 59.0 \\
\hline Test A-3 & 414 & 934 & 219 & 225 & 43.2 & 1840 & 2.3 & 22.5 & 50.9 \\
\hline
\end{tabular}

$\mathrm{COD} / \mathrm{SO}_{4}{ }^{2-}=4.35, \mathrm{VFA}$ is the sum of acetate, propionate, butyrate, and valerate. 


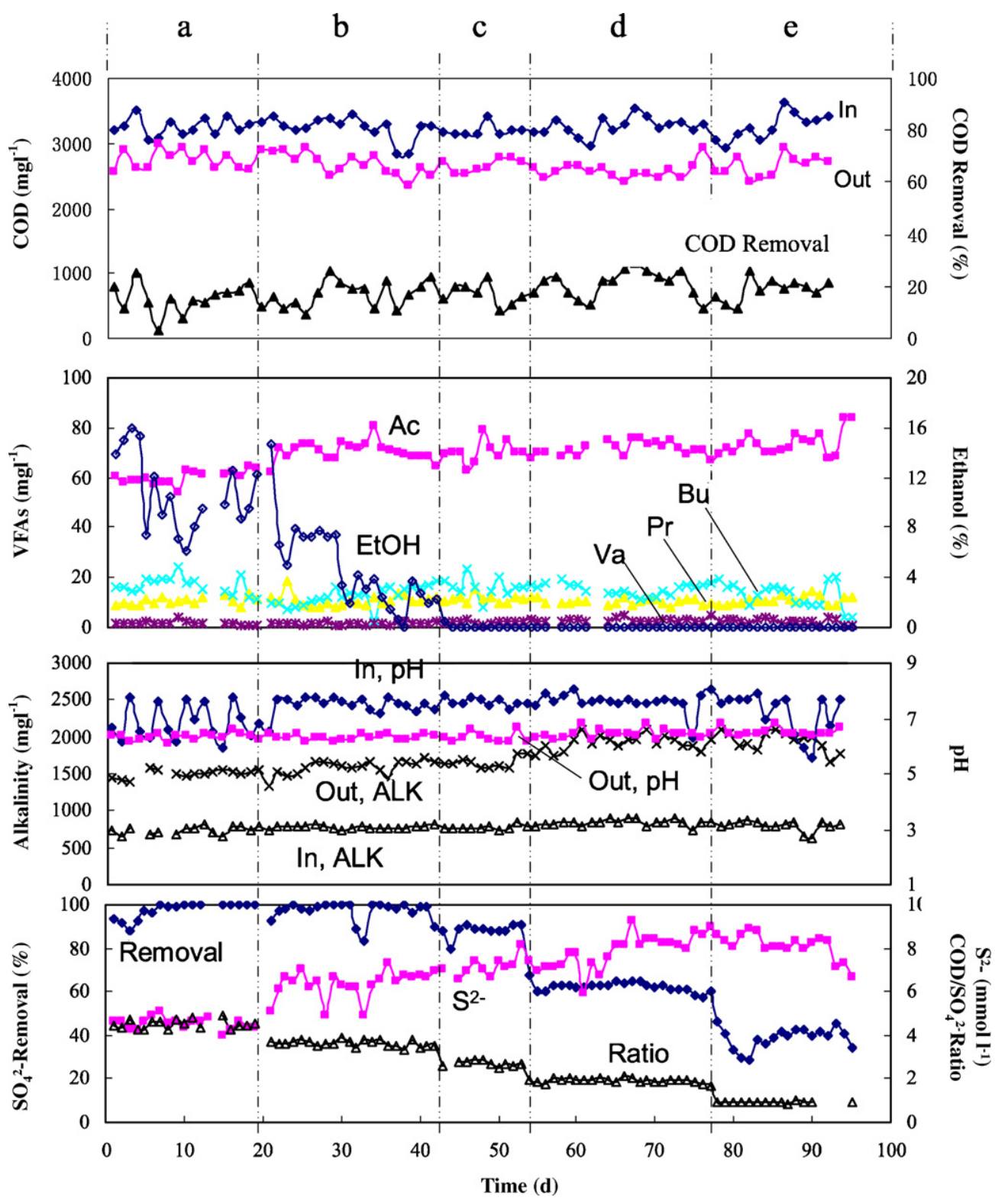

Fig. 1. Parametric changes in continuous test with molasses wastewater. COD $=3220 \mathrm{mg} 1^{-1}$. HRT $=10.6 \mathrm{~h}$. Influent alkalinity $=670 \mathrm{mg} 1^{-1}$. Phases (a-e) correspond to $\mathrm{COD} / \mathrm{SO}_{4}{ }^{2-}$ ratio of $4.5,3.6,2.7,1.9$, and 0.9 , respectively.

condition. Sludge samples collected from the mentioned acidogenic sulfate-reducing reactor under steady-state operation of $\mathrm{COD} / \mathrm{SO}_{4}{ }^{2-}=5 / 1$ was collected and centrifugated $(3000 \mathrm{rpm}$ and $10 \mathrm{~min}$ ) to remove supernatant. The obtained sediment was washed twice using milli-Q water.

Two sets of batch tests were performed. In batch test A, $25 \mathrm{ml}$ sediment with $25 \mathrm{ml}$ substrates (molasses wastewater, acetate, ethanol, propionate, butyrate, or lactate of initial concentrations listed in Table 3) were fed to the culture bottles with sulfate concentration fixed at $742 \mathrm{mg} \mathrm{l}^{-1}$. In batch test B, the test was started with $25 \mathrm{ml}$ molasses wastewater of COD $3220 \mathrm{mgl}^{-1}$ dosed with $25 \mathrm{ml}$ above-mentioned sediment. In test B-1 no sulfate was added. In test B-2, sulfate of concentration $742 \mathrm{mg}^{-1}$ was added initially. In test B-3, sulfate of concentration $742 \mathrm{mg}^{-1}$ was added only on hour 16 of fermentation. All bottles were sealed and incubated on shaken table at $35^{\circ} \mathrm{C}$ and sampled regularly.
To investigate the utilizing capability of the enriched ASRB on ethanol and the VFAs, sludge samples collected from the ASRB enriched bioreactor under steady-state operation of $\mathrm{COD} / \mathrm{SO}_{4}{ }^{2-}=1 / 1$ was collected and centrifugated $(3000 \mathrm{rpm}$ and $10 \mathrm{~min}$ ) to remove supernatant. The obtained sediment was washed twice using milli-Q water and tested as those for test B (named test C).

\subsection{Analytical methods}

The chemical oxygen demand (COD), biochemical oxygen demand (BOD), mixed liquor suspended solids (MLSS), MLVSS, and $\mathrm{pH}$ of suspensions were determined according to Standard Methods [13]. The $\mathrm{H}_{2} \mathrm{~S}$ gas was analyzed using a GC-122 gas chromatography (Shanghai Analytical Apparatus Corporation, Shanghai, China) with a thermal conductivity 
Table 3

Metabolites for batch test B

\begin{tabular}{|c|c|c|c|c|c|c|c|c|c|c|}
\hline \multirow[t]{2}{*}{ Substrate } & \multicolumn{2}{|c|}{ Initial concentration $\left(\mathrm{mg} \mathrm{l}^{-1}\right)$} & \multicolumn{6}{|c|}{ End product (mg COD $\left.{ }^{-1}\right)$} & \multirow[t]{2}{*}{$\mathrm{SO}_{4}{ }^{2-}$ removal ratio $(\%)$} & \multirow[t]{2}{*}{$\mathrm{S}^{2-}\left(\mathrm{mg} \mathrm{l}^{-1}\right)$} \\
\hline & COD & $\mathrm{SO}_{4}{ }^{2-}$ & $\mathrm{EtOH}$ & Acetate & Propionate & Butyrate & Valerate & $\mathrm{EtOH}+\mathrm{VFA}$ & & \\
\hline $\mathrm{EtOH}$ & 4150 & 742 & - & 969 & 57.6 & 13.6 & 7.60 & 1050 & 99.9 & 28.2 \\
\hline Acetate & 3020 & 742 & 5.61 & - & 156 & 64.2 & 25.7 & 252 & 7.5 & 0.64 \\
\hline Propionate & 3420 & 742 & 16.9 & 121 & - & 53.6 & 12.3 & 203 & 22.2 & 3.84 \\
\hline Butyrate & 3780 & 742 & 0.0 & 76.5 & 39.8 & - & 7.26 & 124 & 12.0 & 0.64 \\
\hline Lactate & 3500 & 742 & 14.8 & 525 & 405 & 22.7 & 13.8 & 980 & 97.8 & 26.2 \\
\hline
\end{tabular}

The substrate indicates the sole carbon source used in the test. VFA is the sum of acetate, propionate, butyrate, and valerate.

detector. Ethanol and volatile fatty acids (VFA) were also analyzed by a GC-122 gas chromatography using a flameionization detector (FID). The separation was accomplished by a 2.0-m stainless steel column packed with GDX103 $(60 / 80$ mesh). Nitrogen was the carrier gas at a flow rate of $60 \mathrm{ml} \mathrm{min}^{-1}$. The flow rates of hydrogen and oxygen were 50 and $490 \mathrm{ml} \mathrm{min}^{-1}$, respectively. The temperatures for detector and oven were $210^{\circ} \mathrm{C}$ and $190^{\circ} \mathrm{C}$, respectively [14]. Sulfate concentration in suspension was determined using an ion exchange chromatography (CDD-6A, Shimadzu, Shimpack IC-AI, column temperature $40{ }^{\circ} \mathrm{C}$, mobile phase $2.5 \mathrm{mM}$ of potassium hydrogen phthalate). Sulfide concentration in suspension was determined with the methylene blue colorimetric method [13]. The $\mathrm{H}_{2}$ and $\mathrm{CO}_{2}$ contents in biogas were analyzed by a gas chromatography (Model SC-2 Shanghai Analytical Apparatus Corporation, Shanghai) using a $2.0-\mathrm{m}$ stainless steel column packed with TDS-01 (60/80 mesh) and a thermal conductivity detector (TCD). Nitrogen was used as carrier gas at a flow rate of $70 \mathrm{ml} \mathrm{min}{ }^{-1}$. The temperatures for detector and oven were both at $150{ }^{\circ} \mathrm{C}$. The oxidation-reduction potential (ORP) in the suspension $\left(E_{\mathrm{h}}\right)$ was calculated by the equation: $E_{\mathrm{h}}=E_{\mathrm{c}}+249.1$ $[\mathrm{mV}]$, where $E_{\mathrm{c}}$ was the observed ORP measured by an acidity voltmeter (pHS-25, Shanghai Analytical Apparatus Corporation, Shanghai), and $249.1[\mathrm{mV}]$ was the potential of saturated calomel electrode.

\section{Results and discussion}

\subsection{Continuous tests}

The performance of the acidogenic sulfate-reducing reactor at $\mathrm{HRT}=10.6 \mathrm{~h}$, influent alkalinity of $670 \mathrm{mgl}^{-1}$, and
$\mathrm{COD}=3220 \mathrm{mg}^{-1}$, was shown in Fig. 1 at $\mathrm{COD} / \mathrm{SO}_{4}{ }^{2-}$ ratio of $4.5,3.6,2.7,1.9$, and 0.9 . At $\mathrm{COD} / \mathrm{SO}_{4}{ }^{2-}=4.5$, the sulfate supply was stoichiometrically insufficient hence leading to almost complete removal of sulfate, low level of produced sulfide $\left(4.5 \mathrm{mmoll}^{-1}\right)$, and excess production of ethanol. At $\mathrm{COD} / \mathrm{SO}_{4}{ }^{2-}=3.6$, the removal rate of sulfate was higher than $97 \%$, the sulfide level was increased to $6.4 \mathrm{mmoll}^{-1}$, and the ethanol content was largely reduced. The corresponding acetate content was increased to above $70 \%$. At $\mathrm{COD} / \mathrm{SO}_{4}{ }^{2-}=2.7$, the removal rate of sulfate was reduced to around $88 \%$, the sulfide level was increased to $7.2 \mathrm{mmoll}^{-1}$, while the ethanol content was reduced to zero. $\mathrm{COD} / \mathrm{SO}_{4}{ }^{2-}=1.9$ and 0.9 , the removal rate of sulfate was further reduced to $65 \%$ and $39 \%$, respectively. The corresponding ethanol contents were all zero.

Hence, the above-mentioned tests revealed that at $\mathrm{COD} / \mathrm{SO}_{4}{ }^{2-}=2.7$, the production of acetic acid was significantly enhanced, while that of ethanol was depressed to a rather low level. Ethanol presented in excess as intermediate when sulfate was insufficient in tests with $\mathrm{COD} / \mathrm{SO}_{4}{ }^{2-}>2.7$. Meanwhile, with $\mathrm{COD} / \mathrm{SO}_{4}{ }^{2-}<2.7$, sulfate was in excess to yield acetate was main final product. The metabolic pathway changed from the ethanol-type [14] to the acetate-type fermentation metabolism at $\mathrm{COD} / \mathrm{SO}_{4}{ }^{2-}=2.7$.

\subsection{Batch tests}

The hydrogen contents detected in batch test A were shown in Fig. 2. Table 2 lists the corresponding end product distribution.

In test A-1, since no sulfate was present, SRB could not compete with other strains. Table 2 shows that the ethanol and acetate contributed $35.6 \%$ and $37.7 \%$, respectively, to the end

Table 4

Metabolites for batch test $\mathrm{C}$ with enriched acetate-utilizing SRB

\begin{tabular}{|c|c|c|c|c|c|c|c|c|c|c|}
\hline \multirow[t]{2}{*}{ Substrate } & \multicolumn{2}{|c|}{ Initial concentration $\left(\mathrm{mg} \mathrm{l}^{-1}\right)$} & \multicolumn{6}{|c|}{ End product $\left(\mathrm{mg} \mathrm{l}^{-1}\right)$} & \multirow[t]{2}{*}{$\mathrm{SO}_{4}{ }^{2-}$ removal ratio $(\%)$} & \multirow[t]{2}{*}{$\mathrm{S}^{2-}\left(\mathrm{mg} \mathrm{l}^{-1}\right)$} \\
\hline & COD & $\mathrm{SO}_{4}^{2-}$ & $\mathrm{EtOH}$ & Acetate & Propionate & Butyrate & Valerate & $\mathrm{EtOH}+\mathrm{VFA}$ & & \\
\hline $\mathrm{EtOH}$ & 756 & 400 & 451 & 158 & 38.3 & 6.57 & 0.89 & 655 & 96.2 & 7.36 \\
\hline Acetate & 443 & 400 & 0 & 135 & 12.4 & 9.07 & 0.83 & 157 & 96.4 & 7.68 \\
\hline Propionate & 786 & 500 & 0 & 210 & 450 & 36.1 & 2.04 & 698 & 94.6 & 7.04 \\
\hline Butyrate & 897 & 500 & 0 & 78.9 & 20.4 & 365 & 2.21 & 467 & 95.9 & 7.04 \\
\hline Lactate & 800 & 500 & 0 & 171 & 37.7 & 15.3 & 2.82 & 227 & 96.9 & 7.68 \\
\hline $\begin{array}{l}\text { Molasses } \\
\text { wastewater }\end{array}$ & 800 & 500 & 130 & 554 & 103 & 57.6 & 10.5 & 855 & 97.4 & 9.28 \\
\hline
\end{tabular}

The substrate indicates the sole carbon source used in the test. VFA is the sum of acetate, propionate, butyrate, and valerate. 


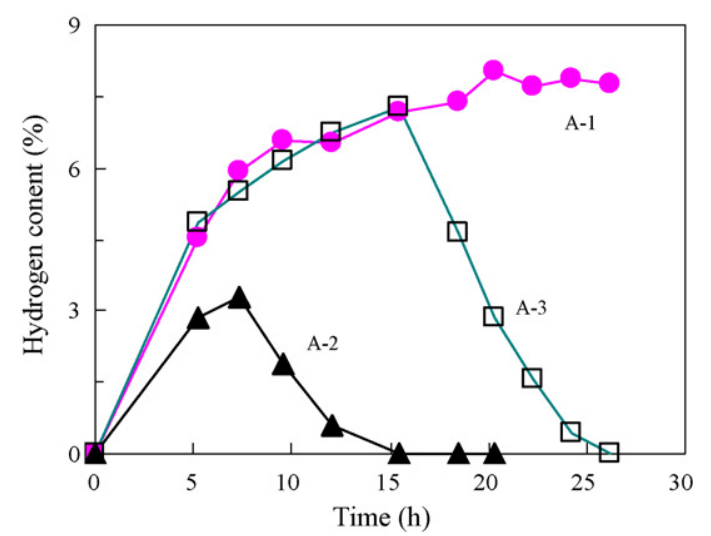

Fig. 2. Hydrogen content in batch test A. (A-1): No sulfate was added. (A-2): Sulfate of $600 \mathrm{mg}^{-1}$ was added. (A-3) Sulfate of $600 \mathrm{mg}^{-1}$ was added on hour 16.

liquid products, accounting for more than $70 \%$ of the total liquid products. $\mathrm{AB}$ produced hydrogen along with acid formation; hence, the hydrogen content in the headspace of culture bottles increased with fermenting time to a plateau of about $7.5 \%$.

In test A-2, with supplied sulfate in the influent, the hydrogen in headspace increased to about $3 \%$ at $7 \mathrm{~h}$ of fermentation, then dropped to very low level at $t>15 \mathrm{~h}$. In test A-3, hydrogen was formed and accumulated in the first $15 \mathrm{~h}$ without sulfate in influent. Then hydrogen was consumed once sulfate was added at $t>15 \mathrm{~h}$. The hydrogen produced by $\mathrm{AB}$ group was consumed by the SRB group when sulfate was present.

The end product distributions in tests $\mathrm{B}$ and $\mathrm{C}$ differed markedly from in test $\mathrm{A}$ (Table 2). The ratios of (acetate/ethanol) were 3.7 and 2.3 for tests $\mathrm{A}-2$ and A-3, higher than 1.1 for test A-1. This occurrence corresponded to the continuous-flow experiments (Fig. 1) that the co-cultured $\mathrm{AB}+\mathrm{SRB}$ system utilized ethanol in sulfate-reducing reaction.

Table 3 lists the sulfate removal ratio and metabolites of batch test $\mathrm{B}$. These tests with different pure substrates corresponded to $\mathrm{COD} / \mathrm{SO}_{4}{ }^{2-}$ ranged 4.1-5.6. As shown in the continuous tests with molasses wastewater (Fig. 1), this sulfate supply should be insufficient, hence leading to almost complete removal of sulfate, low level of produced sulfide, and excess production of ethanol.

When supplied with ethanol and lactate as sole carbon resources, the sulfate removal rates and the total amount of VFAs produced were evidently higher than those supplying with acetate, propionate and butyrate as electron donors. When supplied with ethanol as sole carbon resource, most of the ethanol was converted into acetate. When lactate was fed instead, the end products were mainly acetate and propionate. On the other had, when supplied with acetate, propionate and butyrate as electron donors, few of sulfate was removed while few of fed substrate was converted into other kinds of VFAs, but they could be consumed by SRB population directly. Therefore, ethanol and lactate were SRB population's easily utilized substrate, but acetate, propionate and butyrate were not. More specifically, the utilizing capability of SRB followed ethanol $>$ lactate $>$ propionate $>$ butyrate $>$ acetate. It was indicated that from the viewpoint of thermodynamics, lactate, propionate and butyrate were more available substrates for SRB than acetate [15].

\subsection{Acetic-acid type microbial metabolism}

In the acidogenic sulfate-reducing reactor, VFAs, ethanol and lactic acid could be converted to acetic acid quickly by FSRB and HPA, yielding more acetic acid as the terminal product. A so-called acetic-acid type microbial metabolism was thereby established in the studied acidogenic sulfating-reducing reactor [11].

An interpretation of such an occurrence is as follows. The $\mathrm{H}_{2}$ produced by $\mathrm{AB}$ at degrading $\mathrm{COD}$ could be utilized by HSRB, while the VFAs and lactate produced by $A B$ could be utilized by FSRB and HPA. Similarly, the acetate produced by FSRB and HPA could be utilized by ASRB, and $\mathrm{H}_{2}$ produced by FSRB and HPA could be utilized by HSRB. Therefore, AB, FSRB, HSRB, ASRB and HPA formed bio-chains via the relationship of substrate provision. $\mathrm{AB}$ was at the first level of the bio-chains, FSRB and HPA were at the second, and HSRB and ASRB the third. The HSRB population in acedogenic sulfatereducing reactor acted as an $\mathrm{H}_{2}$-consumer and resulted in low hydrogen partial pressure. Since the available carbon resources (COD) were not limited in acedogenic sulfate-reducing reactor, in order to reserve more energy and get faster growth rate, FSRB competed against other populations and became dominate one. So, FSRB tended to utilize lactate, propionate and butyrate through non-complete-oxidation type metabolic pathway, and produce more acetic acid in the end products. The number and/or activity of acetic acid-utilizing SRB (ASRB) are apparently low in the studied microbial community.

Since acetate is one of preferred substrates for methanogenesis, the increased production of this compound could enhance efficiency of anaerobic treatment in a two-phase acidogenic bioreactor. Restated, if the herein studied sulfate-reducing reactor was adopted as the first phase reactor of the two-phase digesters, the noted acetic-acid type microbial metabolism assists the overall efficiency of the digestion process. However, the possible dampening effects of reduced $\mathrm{pH}$ to the second reactor should be taken into care. Apparently, the accumulated acetate is not beneficial to the treatment capability of sulfateladen wastewater treatment with limited COD supply.

\subsection{Enrichment of acetate-utilizing SRB}

The ASRB population was enriched in a sulfate-reducing acidogenic bioreactor to improve the removal capability of sulfate from wastewater.

The enriched reactor was started up using acetate as the sole carbon source. With influent concentration of acetate (in COD of $\left.1000 \mathrm{mg}^{-1}\right)$ and sulfate $\left(500 \mathrm{mg}^{-1}\right)$ at an HRT of $9.6 \mathrm{~h}$, the sulfate removal rate reached over $80 \%$ on 20 days of enrichment (data not shown).

Table 4 lists the sulfate removal ratio and metabolites of batch test $\mathrm{C}$, with sludge samples collected from the enriched reactor under steady state. The present tests with various pure substrates, which differ from tests $\mathrm{A}$ and $\mathrm{B}$, had a $\mathrm{COD} / \mathrm{SO}_{4}{ }^{2-}$ ratio of 
1.1-1.8. Restated, the present study should be COD-insufficient with reference to the results by continuous tests with molasses wastewater (Fig. 1). Moreover, the studied FSRB could not effectively utilize acetate, propionate, or butyrate as sole carbon source to reduce sulfate. However, the present, enriched ASRB effectively reduced sulfate using each of the five added substrates as the sole carbon source at a COD/SO ${ }_{4}{ }^{2-}$ ratio of 1.1-1.8. As Table 4 lists, the sulfate removal rates thus tested ranged 94.6-96.9\%. The acetate contents were high in metabolites in all tests. Hence, the present ASRB could yield acetate as a product by degrading other VFAs, and further utilized the produced acetate to carbon dioxide to reduce sulfate.

The batch test using molasses wastewater $\left(\mathrm{COD}=800 \mathrm{mgl}^{-1}\right)$ dosed with $500 \mathrm{mgl}^{-1}$ sulfate revealed a high removal rate of sulfate $(97.4 \%)$ and high sulfide concentration $\left(9.3 \mathrm{mgl}^{-1}\right)$. The main metabolites were acetate (64.8\%), ethanol (15.2), and propionate (12.0\%). Restated, with the present ASRB population, COD was found in excess at a low $\mathrm{COD} / \mathrm{SO}_{4}{ }^{2-}=1.6$, significantly lower than the critical value of 2.7 in Fig. 1. Hence, the adoption of enriched ASRB effectively overcomes the barrier to the treatment capability of sulfate-laden wastewater treatment with limited COD supply.

\section{Conclusions}

This work investigated the sulfate reduction reactions in an acidogenic sulfate-reducing reactor at varying $\mathrm{COD} / \mathrm{SO}_{4}{ }^{2-}$ ratios. Continuous test with molasses wastewater as the carbon source revealed that a critical $\mathrm{COD} / \mathrm{SO}_{4}{ }^{2-}$ ratio near 2.7 existed, above which COD in excess, the sulfate was nearly completely removed, yielding extra production of ethanol; below which sulfate was in excess to reduce sulfate removal rate and acetate was largely yielded. Since the SRB consumes hydrogen and volatile fatty acids produced by acidogenic bacteria and hydrogen producing acetogens in degrading COD, an acetic acid-type microbial metabolism was established. The abundant acetate in end product is beneficial to the methanogenesis efficiency in a subsequent methane digester, but limits the sulfate reduction efficiency in utilizing COD. The ASRB was enriched in the reactor and was noted to degrade ethanol, acetate, propionate, butyrate, and valerate to yield sulfate removal rate above $94.6 \%$. Using the enriched ASRB population a low critical $\mathrm{COD} / \mathrm{SO}_{4}{ }^{2-}$ ratio of 1.6 was achieved.

\section{Acknowledgment}

The authors would like to thank the National Natural Science Foundation of China for their supports of this study (Contract No. 50208006).

\section{References}

[1] P.H. Nielsen, Bio-film dynamics and kinetics during high-rate sulfate reduction under anaerobic conditions, Appl. Environ. Microbiol. 53 (1987) 27-32.

[2] E. Chio, J.M. Rim, Competition and inhibition of sulfate reducers and methane producers in anaerobic treatment, Water Sci. Technol. 23 (1991) 1259-1264.

[3] J.P. Maree, W.F. Strydom, Biological sulfate removal in an up-flow packed bed reactor, Water Res. 19 (1985) 1101-1106.

[4] S. Kalyuzhnyi, V. Fedorovich, P.N.L. Lens, L.W.H. Pol, L. Gatze, Mathematical modeling as a tool to study population dynamics between sulfate reducing and methanogenic bacteria, Biodegradation 9 (1998) 187-199.

[5] L.W.H. Pol, P.N.L. Lens, A.J.M. Stams, G. Lettinga, Anaerobic treatment of sulphate-rich wastewaters, Biodegradation 9 (1998) 213-224.

[6] G.F. Parkin, Anaerobic filter treatment of sulfate-containing wastewaters, Water Sci. Technol. 23 (1991) 1283-1291.

[7] O. Mizuno, Y.Y. Li, T. Noike, The behavior of sulfate-reducing bacteria in acidogenic phase of anaerobic digestion, Water Res. 32 (1998) 1626-1634.

[8] Y.Y. Li, H.H.P. Fang, Interactions between methanogenic, sulfate-reducing and syntrophic acetogenic bacteria in the anaerobic degradation of benaozte, Water Res. 30 (1996) 1555-1562.

[9] O. Mizuno, Y.Y. Li, T. Noike, Effects of sulfate concentration and sludge retention time on the interaction between methane production and sulfate reduction for buturate, Water Sci. Technol. 30 (1994) 45-54.

[10] A.J. Wang, Quantification and control of restrictive ecological factors in acidogenic de-sulfate bioreactor, J. Harbin Inst. Technol. 9 (2002) 32-37.

[11] A.J. Wang, N.Q. Ren, Q.L. Zhao, J.C. Huang, Role of sulfate-reducing bacteria in acidogenic bioreactor. Int. J. Environ. Pollut., in press.

[12] S. Vladislav, T. Sava, Application of fluidized carrier to bacterial sulphate reduction in industrial wastewaters purification, Biotechnol. Tech. 6(1992) 91-96

[13] APHA, Standards Methods for the Examination of Water and Wastewater, 19th ed., American Public Health Association, Washington, DC, USA, 1995.

[14] N. Ren, B. Wang, J.C. Huang, Ethanol-type fermentation from carbonhydrate in high rate acidogenic reactor, Biotechnol. Bioeng. 54 (1997) 428-433.

[15] L.L. Barton, Sulfate-Reducing Bacteria, Plenum Press, New York, 1995. 